\title{
ESTIMATING THE PROMINENCE OF AHP IN A SELECTED INTERNET SEARCH ENGINE
}

\author{
Yusof Ismail \\ Department of Business Administration \\ Kulliyyah of Economics and Management Sciences \\ International Islamic University Malaysia \\ Gombak, 53100 Kuala Lumpur, MALAYSIA \\ E-mail: yusof.edu@gmail.com
}

\begin{abstract}
Internet has become an instant source of information for almost anyone. By viewing the results of search terms displayed by an Internet Search Engine (ISE), a person may decide his next course of action whether to continue using the Internet, abort or to combine it with other sources of information. The results produced by an ISE can be regarded as an index of relative availability of references. Given a list of suitable search terms, a user will firstly have to decide on the ISE to be used. Due to huge potential references available for given search terms the user has to create heuristics to choose the entries shown on the computer screen. As there are varying breadths and depths of information revealed by various Internet Search Engines (ISE's), this paper will not attempt to make a comparison among ISE's, rather will focus only on a particular search engine and ascertain the results it produces given a list of search terms. Google is chosen as a proxy, being one of the most popular ISE's. By confining to only a search engine, the study affords to control variability among ISE's should multiple ISE's be used. With the search engine placed under control, it is easy to achieve the primary objective of the study, i.e., to ascertain availability of relative breadth of sub-themes of Analytic Hierarchy Process (AHP) in Google. It is natural for user, especially researcher to be concerned with number, quantity. If there is seemingly abundant literature, one would be motivated to pursue research along the theme or sub-theme. In this study, the strength of presence of a sub-theme is measured by using two measures: (i) result of a sub-theme of AHP over the sub-theme itself, and (ii) result of the sub-theme over the total results generated for all of the thirty six sub-themes used in the search. This study controlled biasness in specifying the sub-themes of AHP by adopting the sub-themes or search terms specified by the 2013 AHP conference organizers. This decision helps make the study efficient without with it has to distill the sub-themes by surveying the AHP literature. The data for analysis was gathered by surfing Google on 26 Feb 20138.55 p.m. - 9.26 p.m. Peninsular Malaysian time. The search results were computed to generate two types of ratios specified earlier. A composite index was created using the resulting two types of ratios which are used to classify the efficiency, hence dominance of the original results (hits). Kendall's correlation produced statistically significant correlations between the composite index and Rank of AHP specific and area results. Using indices greater than 1.000 as the base, 6 AHP specific areas occupy the top positions with ratios ranging from 19.341 to $61.574 ; 15$ AHP specific areas occupy the second top positions with ratios ranging from 1.119 to 9.602 , and 14 AHP specific areas occupy the third and last position with indices below 1.000 ranging from 0.050 to 0.894 . The paper includes discussion, implications, limitations, conclusions and suggestions for further research.
\end{abstract}

Keywords: Analytic Hierarchy Process, decision-making, Internet search engine, ratios 


\section{Introduction}

Internet has become an instant source of information (Joseph, 2008) for many irrespective of their profession. By viewing the results of search terms produced by an Internet Search Engine (ISE), a person may decide his next course of action whether to continue using the Internet, abort or to combine it with other sources of information. The results produced by an ISE can be regarded as a crude index of relative availability of references. Given a list of suitable search terms, a user will firstly have to decide on the ISE to be used. Due to huge potential references available for given search terms the user will likely have to create his heuristics to choose the entries displayed on the computer screen.

This paper will focus on the efficiency of Google as a proxy of the Internet search engines (ISE's) in generating AHP specific areas or topics. By using composite indexes proposed in the paper, a user can ascertain efficiency of results for specified search terms. Composite indexes incorporated both ratios, general and specific AHP, by making the former denominator and the latter, numerator.

\section{Literature Review \\ 2.1 Analytic Hierarchy Process (AHP)}

Analytic Hierarchy Process (AHP) is a technique to help (Wolfe, 1986) an individual, a group or an organization makes decision. Saaty (1990) refers to AHP as "a theory of measurement" that uses analytic model to quantify (Partovi 2001) measures for business performance (Cheng \& Heng Li, 2001). As a technique, AHP provides the decision maker insight and rigor unavailable in a purely judgmental analysis (Wolfe, 1986).

Saaty (1990) describes the hierarchical process in the analysis of factors involved in giving a solution to a complex problem. Firstly, a complex problem is decomposed into a multi-level hierarchic structure of objectives, criteria, sub-criteria and alternatives in that order. Secondly, judgmental paired comparisons are made using a scale of absolute magnitudes. Thirdly, a ratio scale of relative magnitudes expressed in priority units is then derived from each set of comparisons. An overall ratio scale of priorities is computed to obtain ranking of the alternatives.

Researchers in AHP have been reinforcing the multiple attribute characteristic of AHP, such as Dey (2001) in his study on inspection and maintenance of cross-country petroleum pipeline and Dabous \& Alkass (2010) in ranking and prioritizing essential steps in bridge management. AHP accommodates the reality of uncertainty, i.e. the existence of multiple factors involved in a decision making process. The decision maker has to make a decision in absence of complete information. Phillips, Martin, Dainty, \& Price (2007) accommodated the multi objective decision making process within the UK construction industry. Also in UK construction industry, Wu, Lee, Tah, and Aouad (2007) employed multi-attribute AHP to determine the priority of the accessibility criteria.

In addition to multi attributes, AHP has been used in different industries, such as petroleum (Dey, 2001), construction (Phillips, Martin, Dainty, \& Price, 2007; Wu, Lee, J.H.M. Tah, and Aouad, 2007), textile (Shyjith, Ilangkumaran, and Kumanan, 2008); bridge construction (Dabous \& Alkass, 2010); and bidding evaluation (Sipahi and Esen, 2010) and a tender decision process (Phillips, Martin, Dainty, \& Price, 2007).

Popularity of AHP as a decision making technique has attracted scholars to combine it with other techniques. Phillips, Martin, Dainty, \& Price (2007) combined AHP with Multi-Attribute Utility Theory (MAUT) and Whole Life Costing (WLC) in a tender decision process. Ordoobadi (2009) combined AHP and Taguchi loss functions to select appropriate supplier. Punniyamoorty, Ponnusamy Mathiyalagan, \& Lakshmi (2012) combined AHP with structural equation modeling (SEM) to develop a new composite 
model for the selection of suppliers. Zaim, Turkyilmaz, Acar, Al-Turki, and Demirel (2012) integrated both AHP and ANP methods in identifying maintenance strategies.

\subsection{Internet Search Engine (ISE)}

A World Wide Web search engine or Internet Search Engine (ISE) is defined as a retrieval service, consisting of a database (or databases) describing mainly resources available on the World Wide Web (WWW), search software and a user interface (Poulter, 1997). Internet has been positioned as an important publication/communication medium (Mettrop \& Nieuwenhuysen, 2001). While it has provided end users with huge amounts of information (Alimohammadi 2009), it also created a need to efficiently determine the relevance of information (Ho \& Goh, 1999) via sort through all the information available on the Internet (Machill, Neuberger, \& Schindler, 2003). According to one estimate, such facility provides speedy search compared to manual search and cost saving of approximately of $£ 25$ million per annum (Creaser, Hamblin, \& Davies 2006).

ISE's help sort through (Machill, Neuberger, \& Schindler, 2003) and retrieve (Dong \& Su, 1997) all the information available on the Internet and should be efficient in displaying search results because users normally conduct short search sessions (Ozmutlu, Ozmutlu, \& Spink 2003). For firms, availability of information in the Internet may help them improve the chances of attracting custom (Rimbach, Dannenberg, \& Bleimann, 2007). Due to availability of superfluous information, evaluation of information resources should be part of Internet searching (Smith, 2012).

Google is currently by far the most popular search engine (Bar-Ilan, 2007; BBC, 2009). In fact, it is the top most used search engine on the World Wide Web (BBC, 2009). It provides relevancy ranking (Norris, 2006); captures text in Web pages (Goldman, 2012) and relies upon its search-results pages called "PageRank" by providing Boolean operators, alternatives, and wildcards search options (Google, 2012). Any ISE should sort results by subject (Oberhelman, 2006) to make it meaningful.

\section{Method}

For this study, the research considers the list of subject areas provided by the AHP conference organizers as valid search terms because they are content experts. This is consistent with the usual basis for deciding that an instrument has content validity, i.e. through expert judgment. After fulfilling the requirement, the instrument is most suitable for measuring concrete and observable behavior (Noe, Hollenbeck, Gerhart, and Wright (2011). By adopting this approach, this study optimizes the naturally available content validators (i.e. AHP conference organizers) and controls variability among potential content experts should they be consulted to derive the list of search terms.

This study used two measures, i.e. search results of the general terms based on the exact words published by the conference organizers, and search results of inserted "AHP" into each of the general search terms. The list of search terms is shown in Table 1. The search of results via Google was obtained on 26 February 2013 from 8.55 p.m. to 9.26 p.m. Peninsular Malaysian time. The data was copied from the computer screen and pasted onto a columnar table. Ratio for each (i) general area and (ii) AHP specific term was computed. Item (i) ratios were computed by dividing the results of a general area into the total of all of the general areas, whereas item (ii) ratios were derived by dividing the results of each $A H P$ specific over the total results of all of the AHP specifics. Later, both (i) and (ii) were rank ordered based on the size of respective ratios. A composite measure that represented both categories of ratios labeled as composite index was produced by treating the ratios of AHP specific as numerator and those of the general area as denominator. The prominence of AHP specific in relation to the general areas is thus established by assessing the magnitude of the composite indices.

\section{Findings}


Results show that AHP specific comprised 0.335 percent of the total results of general areas.

Table 1 shows the results and corresponding ratios of two measures under study: (i) general areas, and (ii) AHP specifics. Out of the list of 36 general areas suggested by the conference organizers, one area, i.e. "AHP" was excluded since it had no equivalent generic term.

Table 1 Google results and ratios of general area and AHP specific

\begin{tabular}{|c|c|c|c|c|}
\hline Areas & $\begin{array}{l}\text { General } \\
\text { Results }\end{array}$ & $\begin{array}{c}\text { General } \\
\text { Ratio }\end{array}$ & $\begin{array}{c}\text { AHP } \\
\text { Results }\end{array}$ & $\begin{array}{l}\text { AHP } \\
\text { Ratio }\end{array}$ \\
\hline Sports & 4000000000 & 38.796 & 12000000 & 34.728 \\
\hline Finance & 1210000000 & 11.736 & 4390000 & 12.704 \\
\hline Information Management & 1170000000 & 11.348 & 2590000 & 7.495 \\
\hline Project Management & 900000000 & 8.729 & 1460000 & 4.225 \\
\hline Transportation & 698000000 & 6.770 & 1220000 & 3.531 \\
\hline Human Resources Management & 391000000 & 3.792 & 972000 & 2.813 \\
\hline Group Decision Making & 262000000 & 2.541 & 970000 & 2.807 \\
\hline Military Applications & 235000000 & 2.279 & 946000 & 2.738 \\
\hline Strategic Management & 232000000 & 2.250 & 861000 & 2.492 \\
\hline Social Issues and Applications & 162000000 & 1.571 & 843000 & 2.44 \\
\hline Disaster Management & 109000000 & 1.057 & 822000 & 2.379 \\
\hline Location Decisions & 107000000 & 1.038 & 819000 & 2.370 \\
\hline Marketing Decisions & 99800000 & 0.968 & 760000 & 2.199 \\
\hline Health Technology Assessment & 88200000 & 0.855 & 702000 & 2.032 \\
\hline Employee Recruitment & 85600000 & 0.830 & 672000 & 1.945 \\
\hline Medical Decision Making & 85100000 & 0.825 & 539000 & 1.560 \\
\hline Total Quality Management & 78000000 & 0.757 & 529000 & 1.531 \\
\hline Risk/Uncertainty & 65800000 & 0.638 & 499000 & 1.444 \\
\hline Application in Healthcare Services & 58100000 & 0.564 & 465000 & 1.346 \\
\hline Conflict Resolution & 45400000 & 0.440 & 332000 & 0.961 \\
\hline Purchasing and Supply Chain & 44300000 & 0.430 & 323000 & 0.935 \\
\hline Production Planning and Management Safety & 36300000 & 0.352 & 303000 & 0.877 \\
\hline Engineering and Technological Applications & 31500000 & 0.306 & 290000 & 0.839 \\
\hline Decision Support Systems Aid & 21300000 & 0.207 & 256000 & 0.741 \\
\hline Behavioral Decision Making & 20100000 & 0.195 & 234000 & 0.677 \\
\hline Integration of with Other Methods & 17700000 & 0.172 & 181000 & 0.524 \\
\hline Forecasting and Prediction & 12700000 & 0.123 & 170000 & 0.492 \\
\hline Generalization of Neural Firing & 9580000 & 0.093 & 78400 & 0.227 \\
\hline Projects Prioritization & 6550000 & 0.064 & 73900 & 0.214 \\
\hline $\begin{array}{l}\text { General Resource Allocation and } \\
\text { Optimization }\end{array}$ & 5850000 & 0.057 & 64900 & 0.188 \\
\hline Entrepreneurship and Small Business & 5370000 & & 61900 & \\
\hline Management & & 0.052 & & 0.179 \\
\hline Performance Measurement/Management & 5200000 & 0.050 & 52800 & 0.153 \\
\hline
\end{tabular}




\begin{tabular}{|c|c|c|c|c|}
\hline Environmental Applications and Sustainability & 4570000 & 0.044 & 51900 & 0.15 \\
\hline Utility Theory: A Comparison & 3920000 & 0.038 & 21700 & 0.063 \\
\hline \multirow[t]{2}{*}{ Tender Evaluation } & 3290000 & 0.032 & 1200 & 0.003 \\
\hline & 10310230000 & & 34554700 & \\
\hline
\end{tabular}

The ratios of generic areas over their total labeled as "Areas Ratio" and the generic topics with AHP over their total labeled as AHP specific are shown in columns (4) and (2) of Table 2, respectively.

For example, for general area "Application in Healthcare Services," its general ratio (its results over total results of all of the 35 terms) in column (4) is 0.564 , whereas when the term "AHP" was added to the same subject area, the resulting ratio is 34.728 (column 6). The AHP specific ratio is obtained by dividing the combined AHP and general area over the total of all AHP and respective general areas. In this particular instance, the combined AHP and generic area generated more efficient and productive result because its ratio is higher (34.728) than the other (0.564). Comparative position between the AHP specific and the general area is reflected in the composite index (i.e. AHP specific ratio and general areas ratio).

Table 2: Generic and Specific AHP Ratios, Ranks, and Composite Ratios

\begin{tabular}{|c|c|c|c|c|c|}
\hline AREAS & $\begin{array}{c}\text { (2) } \\
\text { Area Plus } \\
\text { AHP } \\
\text { Ratio } \\
\end{array}$ & $\begin{array}{c}(3) \\
\text { Area Plus } \\
\text { AHP } \\
\text { Rank } \\
\text { position }\end{array}$ & $\begin{array}{c}(4) \\
\\
\text { Areas } \\
\text { Ratio }\end{array}$ & $\begin{array}{c}\text { (5) } \\
\text { Areas } \\
\text { Rank }\end{array}$ & $\begin{array}{c}\text { (6) } \\
\text { Composite } \\
\text { index* }\end{array}$ \\
\hline Application in Healthcare & & & & & \\
\hline $\begin{array}{l}\text { Services } \\
\text { Environmental Applications }\end{array}$ & 34.728 & 1 & 0.564 & 19 & 61.574 \\
\hline $\begin{array}{l}\text { and Sustainability } \\
\text { Performance }\end{array}$ & 2.492 & 9 & 0.044 & 33 & 56.636 \\
\hline $\begin{array}{l}\text { Measurement/Management } \\
\text { Integration of with Other }\end{array}$ & 2.44 & 10 & 0.050 & 32 & 48.800 \\
\hline Methods & 7.495 & 3 & 0.172 & 26 & 43.576 \\
\hline $\begin{array}{l}\text { General Resource Allocation } \\
\text { and Optimization }\end{array}$ & 2.37 & 12 & 0.057 & 30 & 41.579 \\
\hline Forecasting and Prediction & 2.379 & 11 & 0.123 & 27 & 19.341 \\
\hline \multicolumn{6}{|c|}{ Second position } \\
\hline $\begin{array}{l}\text { Conflict Resolution } \\
\text { Generalization of Neural }\end{array}$ & 4.225 & 4 & 0.440 & 20 & 9.602 \\
\hline Firing & 0.839 & 23 & 0.093 & 28 & 9.022 \\
\hline Behavioral Decision Making & 1.444 & 18 & 0.195 & 25 & 7.405 \\
\hline $\begin{array}{l}\text { Purchasing and Supply Chain } \\
\text { Engineering and }\end{array}$ & 2.807 & 7 & 0.430 & 21 & 6.528 \\
\hline $\begin{array}{l}\text { Technological Applications } \\
\text { Decision Support Systems }\end{array}$ & 1.531 & 17 & 0.306 & 23 & 5.003 \\
\hline $\begin{array}{l}\text { Aid } \\
\text { Utility Theory: A }\end{array}$ & 0.935 & 21 & 0.207 & 24 & 4.517 \\
\hline Comparison & 0.153 & 32 & 0.038 & 34 & 4.026 \\
\hline Projects Prioritization & 0.227 & 28 & 0.064 & 29 & 3.547 \\
\hline Location Decisions & 2.813 & 6 & 1.038 & 12 & 2.710 \\
\hline Marketing Decisions & 1.56 & 16 & 0.968 & 13 & 1.612 \\
\hline Production Planning and & & & & & \\
\hline Management Safety & 0.492 & 27 & 0.352 & 22 & 1.398 \\
\hline Risk/Uncertainty & 0.877 & 22 & 0.638 & 18 & 1.375 \\
\hline Entrepreneurship and Small & 0.063 & 34 & 0.052 & 31 & 1.212 \\
\hline
\end{tabular}




\begin{tabular}{|c|c|c|c|c|c|}
\hline \multicolumn{6}{|l|}{ Business Management } \\
\hline Military Applications & 2.738 & 8 & 2.279 & 8 & 1.201 \\
\hline Information Management & 12.704 & 2 & 11.348 & 3 & 1.119 \\
\hline \multicolumn{6}{|c|}{ Third position } \\
\hline Total Quality Management & 0.677 & 25 & 0.757 & 17 & 0.894 \\
\hline Group Decision Making & 2.199 & 13 & 2.541 & 7 & 0.865 \\
\hline Transportation & 3.531 & 5 & 6.770 & 5 & 0.522 \\
\hline \multicolumn{6}{|l|}{ Social Issues and } \\
\hline Applications & 0.524 & 26 & 1.571 & 10 & 0.334 \\
\hline Strategic Management & 0.741 & 24 & 2.250 & 9 & 0.329 \\
\hline \multicolumn{6}{|l|}{ Human Resources } \\
\hline Management & 0.961 & 20 & 3.792 & 6 & 0.253 \\
\hline \multicolumn{6}{|l|}{ Health Technology } \\
\hline Assessment & 0.214 & 29 & 0.855 & 14 & 0.250 \\
\hline Employee Recruitment & 0.188 & 30 & 0.830 & 15 & 0.227 \\
\hline Medical Decision Making & 0.179 & 31 & 0.825 & 16 & 0.217 \\
\hline Finance & 2.032 & 14 & 11.736 & 2 & 0.173 \\
\hline Project Management & 1.346 & 19 & 8.729 & 4 & 0.154 \\
\hline Disaster Management & 0.15 & 33 & 1.057 & 11 & 0.142 \\
\hline Tender Evaluation & 0.003 & 35 & 0.032 & 35 & 0.094 \\
\hline Sports & 1.945 & 15 & 38.796 & 1 & 0.050 \\
\hline
\end{tabular}

*Composite index = AHP specific ratio/General area ratio

Results show negative correlation between Rank of areas and Composite index (i.e., AHP specific vs. General area ratios; $\alpha=-.500, \mathrm{p}$-value $=.002)$ and with area results $(\alpha=-.-.551, \mathrm{p}=.001)$ (see Table 3 ). This suggests that general area results may not be useful in relation to composite index. Rank of $A H P$ specific is positively correlated with composite index $(\alpha=-. .471, \mathrm{p}=.001)$, thus signifying its 'presence' in the composite index. The significance of composite index is supported by Rank of AHP specific and general area results. The composite index is positively correlated with AHP specific $(\alpha=-. .471, \mathrm{p}=.004)$ and area results $(\alpha=-. .563, p=.000)$; however, it shows negative relationship with Rank of areas $(\alpha=-.-$ $.500, \mathrm{p}=.002)$. Area results shows negative correlation with Rank of areas $(\alpha=-.-.551, \mathrm{p}=.001)$. Overall, the analysis suggests that composite index may be used as an indicator of efficiency of AHP search results.

Table 3 Correlations between ranks and ratios

\begin{tabular}{|c|c|c|c|c|c|}
\hline \multicolumn{6}{|c|}{ Correlations } \\
\hline & & \multirow{4}{*}{$\begin{array}{l}\text { Rank of } \\
\text { general } \\
\text { areas }\end{array}$} & \multirow{2}{*}{\multicolumn{3}{|c|}{$\begin{array}{l}\text { Composite } \\
\text { index }\end{array}$}} \\
\hline & & & & & \\
\hline & & & & (AHP specific & \\
\hline & & & $\begin{array}{c}\text { Rank of } A H P \\
\text { specifics }\end{array}$ & $\begin{array}{l}\text { vs. General area } \\
\text { ratios) }\end{array}$ & $\begin{array}{c}\text { General } \\
\text { area results }\end{array}$ \\
\hline \multirow[t]{3}{*}{ Rank of general areas } & Pearson Correlation & 1 & .206 & $-.500^{* *}$ & $-.551^{* *}$ \\
\hline & Sig. (2-tailed) & & .234 & .002 & .001 \\
\hline & $\mathrm{N}$ & 35 & 35 & 35 & 35 \\
\hline \multirow{3}{*}{ Rank of $A H P$ specific } & Pearson Correlation & .206 & 1 & $.471^{* *}$ & -.072 \\
\hline & Sig. (2-tailed) & .234 & & .004 & .683 \\
\hline & $\mathrm{N}$ & 35 & 35 & 35 & 35 \\
\hline Composite index & Pearson Correlation & $-.500^{* *}$ & $.471^{* *}$ & 1 & $.563^{* *}$ \\
\hline (AHP specific ratios over & Sig. (2-tailed) & .002 & .004 & & .000 \\
\hline Generic area ratios) & $\mathrm{N}$ & 35 & 35 & 35 & 35 \\
\hline \multirow[t]{2}{*}{ Area results } & Pearson Correlation & $-.551^{* *}$ & -.072 & $.563^{* *}$ & 1 \\
\hline & Sig. (2-tailed) & .001 & .683 & .000 & \\
\hline
\end{tabular}




\begin{tabular}{ccccc}
$\mathrm{N}$ & 35 & 35 & 35 & 35 \\
\hline$* *$. Correlation is significant at the 0.01 level (2-tailed). & & &
\end{tabular}

Based on the conclusion of correlation results (Table 3), one can make a decision of the quality or efficiency of the search terms by referring to the composite indices. Using indices greater than 1.000 as the cut-off point, 6 search items occupy the top positions (see Table 2) with ratios ranging from 19.341 to 61.574; 15 items occupy the second top positions with ratios ranging from 1.119 to 9.602 , and 14 items occupy the third and last position with indices below 1.000 ranging from 0.050 to 0.894 .

\section{Limitations of study}

The study assumes that the search results show distinct and non repetitive contents. However, in reality search engines may contain repetitive and similar items. By factoring this out or minimizing it will enhance the value of search results. One study found that the search results did contain eradicate erroneous links and duplicated documents (Ho and Goh 1999). Due to increasing reliance on the Internet as a publication/communication medium, the fluctuations in the results should be minimized (Mettrop \& Nieuwenhuysen, 2001). While it is feasible to address the issue of fluctuations in results, the latter remains a key challenge (Martinez-Gil \& Aldana-Montes 2012). It is indeed very ambitious for search engines, Google included, to meet the information needs of every user, consequently experiments on this issue are expected to continue; an author (Alimohammadi, 2003) suggested use of meta-tag as an alternative solution.

\section{Conclusion}

Google search revealed three categories of productive search results on AHP based on the composite index, which in turn relied on ratios. The composite index incorporated two measures, i.e., the statistically validated ranks of AHP specific and the Google' general area results. Based on composite indexes greater than 1.000 as the benchmark, the procedure generated 6 AHP specific areas that occupy the top positions and they are healthcare services, environmental and sustainability, performance management, integration with other methods resource allocation and optimization, and forecasting and prediction. Second prominent categories include conflict resolution, generalization of neural firing, and behavioral decision making. The last prominent categories include Total Quality Management, Group Decision Making, and Transportation.

\section{REFERENCES}

Alimohammadi. D. (2009). Did webrings die? An exploratory study. Library Hi Tech News Volume: 26 Issue: $10 \mathrm{pp} 8-11$.

Alimohammadi, D. (2003). Meta-tag: a means to control the process of Web indexing. Online Information Review Volume: 27 Issue: 4 , pp238-242.

Bar-Ilan, J. ( 2007). Manipulating search engine algorithms: the case of Google. Journal of Information, Communication and Ethics in Society Volume: 5 Issue: 2/3 pp.155-166.

BBC (2009). "Microsoft and Yahoo seal web deal". BBC Mobile News, July 29, Retrieved 10 may 2012.

Cheng, W.W.L. \& Li, H.(2001). Development of a conceptual model of construction partnering,

Engineering. Construction and Architectural Management Volume: 8 Issue: 4 pp292-303. 
Creaser, C, Hamblin,Y, \& Davies, J.E. (2006). An assessment of potential efficiency gains through online content use. Program: electronic library and information systems Volume: 40 Issue: 2 pp178-189.

Dabous, S.A. \& Alkass, S. (2010). A multi-attribute ranking method for bridge management. Engineering, Construction and Architectural Management Volume: 17 Issue: 3 pp.282 - 291.

Dey, A.K. (2001). Understanding and Using Context. Personal and Ubiquitous Computing Journal, Vol. 5 (1), pp. 4-7.

Dong, X \& Su, L.T. (1997). Search engines on the world wide web and information retrieval from the internet: a review and evaluation. Online Information Review Volume: 21 Issue: 21997 pp.67-82.

Goldman, D. (2012). "Bing fires at Google with new social search". CNN Money. Retrieved 10 May.

Google. (2012). ^"'"...The *, or wildcard, is a little-known feature that can be very powerful..."'". Google.co.nz. Retrieved August 4.

Ho, CW \& Goh, A. (1999). Jamaica: a World Wide Web profiler. Internet Research Volume: 9 Issue: 2 pp.129 - 139 .

Martinez-Gil, J \& Aldana-Montes, J.F. (2012). Smart combination of web measures for solving semantic similarity problems. Online Information Review Volume: 36 Issue: 5 pp724-738.

Machill, M, Neuberger, C, \& Schindler, F. (2003). Transparency on the Net: functions and deficiencies of Internet search engines. info Volume: 5 Issue: 1 pp52-74.

Mettrop, W \& Nieuwenhuysen, P. (2001). Internet search engines - fluctuations in document accessibility Type: General review. Journal of Documentation Volume: 57 Issue: 5 pp623-651.

Noe, R.A., Hollenbeck, J.R., Gerhart, B. and Wright, P.M. (2011). Fundamentals of Human Resource Management $\left(4^{\text {th }}\right.$ Ed. $)$. McGrawHill.

Norris, B.P. (2006). Google: Its Impact on the Library. Library Hi Tech News Volume: 23 Issue: 9 pp911.

Oberhelman, D.D. (2006). The time machine: federated searching today and tomorrow. Reference Reviews Volume: 20 Issue: 3 pp6-8.

Ordoobadi, S. (2009). Evaluation of advanced manufacturing technologies using Taguchi's loss functions, Journal of Manufacturing Technology Management Volume: 20 Issue: 3 pp367 - 384.

Ozmutlu, S, Ozmutlu,HC, \& Spink, A. (2003). Are people asking questions of general Web search engines? Online Information Review Volume: 27 Issue: 6 pp396-406.

Phillips, S, Martin, J, Dainty, ARJ, and Price, ADF. (2007). Uncertainty in best value decision making. Journal of Financial Management in Property and Construction, Volume 12 No 2, pp63-72.

Poulter, A. (1997). The design of World Wide Web search engines: a critical review. Program: electronic library and information systems Volume: 31 Issue: 2 pp131 - 145. 
Punniyamoorty, M, Mathiyalagan, P, Lakshmi, G. (2012). A combined application of structural equation modeling (SEM) and analytic hierarchy process (AHP) in supplier selection. Benchmarking: An International Journal Volume: 19 Issue: 1 pp70 - 92.

Rimbach, F, Dannenberg, M, \& Bleimann, U. (2007). Page ranking and topic-sensitive page ranking: micro-changes and macro-impact. Internet Research Volume: 17 Issue: 1_pp.38-48.

Saaty, T.L. (1990). The Analytic Hierarchy Process in Conflict Management. International Journal of Conflict Management Volume: 1 Issue: 1 pp.47 - 68.

Shyjith, K, Ilangkumaran, M, and Kumanan, S. (2008). Multi-criteria decision-making approach to evaluate optimum maintenance strategy in textile industry. Journal of Quality in Maintenance Engineering Volume: 14 Issue: 4 pp.375 - 386.

Sipahi, S and Esen, O. (2010). A multi-criteria model for bidding evaluation: An alternative selection of the best firms for the presentation of Istanbul 2010. Management Decision, Volume: 48 Issue: 2 pp. 296 313.

Smith, A.G. (2012). Internet search tactics. Online Information Review Volume: 36 Issue: 12012 pp.7 20.

Wolfe, C. (1986). The analytical hierarchy process - an aid to decision making. Mid-American Journal of Business, September, pp. 13-18.

Wu, S, Lee, A, Tah, J.H.M. and Aouad, G. (2007). The use of a multi-attribute tool for evaluating accessibility in buildings: the AHP approach. Facilities, Volume: 25 Issue: 9/10 pp.375 - 389.

Zaim, S, Turkyilmaz, A, Acar, M, Al-Turki, U and Demirel, OF. (2012). Maintenance strategy selection using AHP and ANP algorithms: a case study. Journal of Quality in Maintenance Engineering Volume: 18 Issue: 1 pp. 16-29. 